\title{
MARIUSZ BARANOWSKI
}

Adam Mickiewicz University in Poznan

mariusz.baranowski@amu.edu.pl

ANNA ODROWAZ-COATES

The Maria Grzegorzewska Pedagogical University in Warsaw

acoates@aps.edu.pl

\section{INTRODUCTION TO SOCIETY REGISTER}

\section{Dear Reader,}

Thank you for reaching out for this novel journal in the field of social sciences and for taking your time to study this first issue of Society Register. We would like to extend our thanks to both the authors and reviewers who contributed their time and expertise to this initial issue. As you will note, the journal follows a rigorous double blind peer review procedure, striving for a level of scientific excellence that could not be reached without the diligent commitment of the authors.

In this issue, one may find both theoretical and empirical papers, followed by three book reviews. The issue opens with papers in English, which is our target language, followed by papers in Polish. There are papers from authors based in Algeria, India, Iran, UK, USA, Vietnam, Turkey and Poland, who are all social researchers and active observers of social life at different stages of their academic and professional career.

We present you with a selection of current social, educational, political and philosophical topics in a socio-historical context: intercultural issues, identity and resistance, social systems, social control and rehabilitation, communication, reflexivity, spirituality and religion, social justice, issues relevant to education and care, politics, language and even poetry.

We aim to become an open forum of scientific thought exchange, inviting scholars with a wide range of experience within the rich field of social sciences, embracing subjects that are both central and peripheral to the further development of disciplines such as sociology, comparative pedagogy, social psychology, anthropology, education, social policy, international relations and philosophy.

What makes us unique in Central Europe is that we wish to offer avenues to be heard and visible for early career scholars alongside established authorities in these fields of expertise. We would like to be comprehensive internationally and in order to do so we promote comparative studies. 
We hope that you will find this journal appealing, thought provoking and open to further discussion. We look forward to to hear from you with comments, ideas, paper proposals and offers of future cooperation. We are open to all your calls and happy to be of assistance.

With warmest wishes,

Mariusz Baranowski \& Anna Odrowaz-Coates

The Editors 